\title{
Xylitol production from waste xylose mother liquor containing miscellaneous sugars and inhibitors: one-pot biotransformation by Candida tropicalis and recombinant Bacillus subtilis
}

Hengwei Wang ${ }^{1}$, Lijuan $\mathrm{Li}^{2}$, Lebin Zhang ${ }^{2}$, Jin An² ${ }^{2}$ Hairong Cheng ${ }^{2 *}$ and Zixin Deng ${ }^{2}$

\begin{abstract}
Background: The process of industrial xylitol production is a massive source of organic pollutants, such as waste xylose mother liquor (WXML), a viscous reddish-brown liquid. Currently, WXML is difficult to reuse due to its miscellaneous low-cost sugars, high content of inhibitors and complex composition. WXML, as an organic pollutant of hemicellulosic hydrolysates, accumulates and has become an issue of industrial concern in China. Previous studies have focused only on the catalysis of xylose in the hydrolysates into xylitol using one strain, without considering the removal of other miscellaneous sugars, thus creating an obstacle to subsequent large-scale purification. In the present study, we aimed to develop a simple one-pot biotransformation to produce high-purity xylitol from WXML to improve its economic value.
\end{abstract}

Results: In the present study, we developed a procedure to produce xylitol from WXML, which combines detoxification, biotransformation and removal of by-product sugars (purification) in one bioreactor using two complementary strains, Candida tropicalis X828 and Bacillus subtilis Bs12. At the first stage of micro-aerobic biotransformation, the yeast cells were allowed to grow and metabolized glucose and the inhibitors furfural and hydroxymethyl furfural (HMF), and converted xylose into xylitol. At the second stage of aerobic biotransformation, B. subtilis Bs 12 was activated and depleted the by-product sugars. The one-pot process was successfully scaled up from shake flasks to 5, 150 L and $30 \mathrm{~m}^{3}$ bioreactors. Approximately $95 \mathrm{~g} / \mathrm{L}$ of pure xylitol could be obtained from the medium containing $400 \mathrm{~g} / \mathrm{L}$ of WXML at a yield of $0.75 \mathrm{~g} / \mathrm{g}$ xylose consumed, and the by-product sugars glucose, $\mathrm{L}$-arabinose and galactose were depleted simultaneously.

Conclusions: Our results demonstrate that the one-pot procedure is a viable option for the industrial application of WXML to produce value-added chemicals. The integration of complementary strains in the biotransformation of hemicellulosic hydrolysates is efficient under optimized conditions. Moreover, our study of one-pot biotransformation also provides useful information on the combination of biotechnological processes for the biotransformation of other compounds.

Keywords: Waste xylose mother liquor, One-pot biotransformation, Xylitol, Candida tropicalis, Bacillus subtilis

\footnotetext{
${ }^{*}$ Correspondence: chrqra@sjtu.edu.cn

${ }^{2}$ State Key Laboratory of Microbial Metabolism, School of Life Sciences

and Biotechnology, Shanghai Jiao Tong University, Shanghai 200240,

China

Full list of author information is available at the end of the article
} 


\section{Background}

Commercially available xylitol is mainly produced by the hydrogenation of xylose under conditions of high temperature $\left(80-140{ }^{\circ} \mathrm{C}\right.$ ) and high pressure (up to 50 atm) [1-4]. The intermediate sugar xylose is extracted from hydrolysates of corn cobs and sugarcane bagasse through acid hydrolysis, condensation and crystallization. These processes are massive sources of organic pollutants such as waste xylose mother liquor (WXML), a viscous reddish-brown liquid. WXML mainly contains sugars (in $\mathrm{w} / \mathrm{w})$, such as xylose (35-40\%), L-arabinose (10-15\%), glucose (8-10\%) and galactose (8-10\%), and other organic components such as furfural and hydroxymethyl furfural (HMF), the concentrations of which depend on the factory as well as different batches. Generally, WXML contains approximately $60-75 \%$ (in w/w) total sugars, among which xylose accounts for 50-70 \% [5]. However, xylose, the most prevalent sugar in WXML, cannot be extracted by crystallization due to the high content of other sugars. Currently, WXML is difficult to reuse due to its miscellaneous low-cost sugars, high content of inhibitors and complex composition. In China, 50,00080,000 tons of WXML is estimated to be produced by about ten large factories per year, and this has become an issue of industrial concern.

Attempts have been made to improve the economic value of WXML so as to facilitate its industrial application. One strategy is to individually separate the sugars, such as xylose, L-arabinose and galactose, by the methods of simulated moving bed chromatography and ion exchange chromatography [6, 7]. However, until now, the chromatography method is difficult to scale up in factories, due to its high running costs compared with the low-value sugars as well as its low separation efficiency. Another strategy is to directly transform the sugars, mainly xylose from hemicellulosic hydrolysates, into xylitol by yeast strains or other microbes [8-16]. It has been reported that approximately $100 \mathrm{~g} / \mathrm{L}$ of xylitol can be produced from detoxified horticultural waste hemicellulosic hydrolysates using Candida athensensis SB18, a yeast strain isolated from soil [17]. The furan compounds furfural and HMF, released from dilute acid hydrolysis under severe conditions, are toxic to microorganisms used for the subsequent biotransformation. Treatment with $2-5 \%(\mathrm{w} / \mathrm{v})$ activated charcoal is a classic method to remove such growth inhibitors, but recently developed biological detoxification (biodetoxification) has shown potential in industrial applications due to its low cost $[5,18-20]$. However, it is still difficult to scale up, since a high content of by-product sugars which are left in the biotransformation can significantly reduce the recovery of subsequent xylitol extraction [21-23]. There are two options to removal such by-product sugars by biochemical approaches (Fig. 1a, b). The first scheme is to use one "perfect" strain that can transform xylose to xylitol and consume all of the by-product sugars under the stress of inhibitors (Fig. 1a). The alternative is to use "complementary" strains, one of which could either transform xylose to xylitol, or consume by-product sugars or detoxify the inhibitors (Fig. 1b). The first one seems very simple in terms of processing, but it is sometimes quite difficult to construct such a "perfect" strain. In our previous study, we developed a technical route in which biodetoxification, biotransformation and purification was integrated using C. maltos $a$ and recombinant $B$. subtilis with a disrupted xylose isomerase gene $x y l \mathrm{~A}$. We finally obtained $213 \mathrm{~g} / \mathrm{L}$ of xylitol in a medium containing $250 \mathrm{~g} / \mathrm{L}$ of xylose from WXML in a $5 \mathrm{~L}$ fermentor [5]. However, it needs improvements due to the complexity of the technique. Specifically, centrifugation to clear the broth was necessary following each step so as to carry out next step of catalysis; the use of C. maltosa produced approximately $5 \mathrm{~g} / \mathrm{L}$ of $\mathrm{D}$-arabitol from xylose, thereby reducing the yield of xylitol; and before the last step of
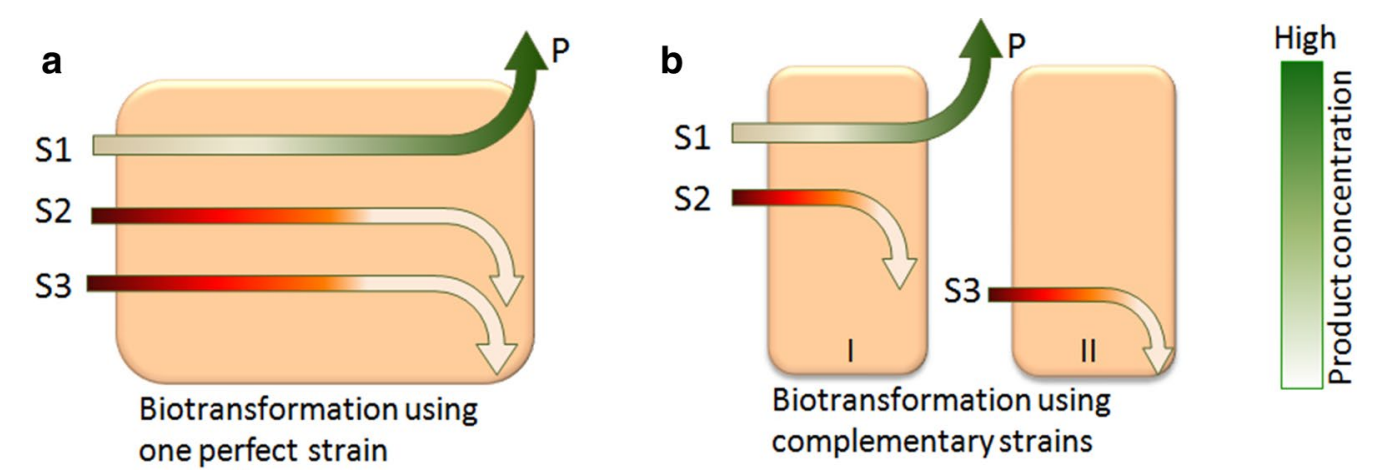

Fig. 1 Scheme of biotransformation by one perfect strain (a) and complementary strains (b). S1 main substrate xylose, S2 by-product sugars, S3 inhibitors, $P$ product, / and // complementary strains 
xylose biotransformation, vacuum evaporation was performed to concentrate the fermentation broth to obtain $250 \mathrm{~g} / \mathrm{L}$ of xylose. This technology is still not suitable for simple large-scale xylitol production from WXML due to its complicated operation and considerable equipment investment.

If pure xylitol can be produced directly from the microbial fermentation of WMXL or hemicellulosic hydrolysates using only one bioreactor, and the inhibitors and by-product sugars can be removed simultaneously, the technique might be simple and competitive enough to be industrialized. In the present study, we aimed to develop a one-pot procedure to produce xylitol from WXML, in which detoxification, biotransformation and purification were carried out in only one bioreactor. To achieve this purpose, we first constructed an integrated biotransformation system using two complementary strains. Secondly, we tested its integration efficiency, optimized the conditions, and developed a two-stage biotransformation, which transformed xylose into xylitol without producing new sugar alcohols, and meanwhile, depleted the inhibitors and by-product sugars. Finally, we successfully scaled up our newly developed one-pot biotransformation from shake flasks to $150 \mathrm{~L}$ and $30 \mathrm{~m}^{3}$ bioreactors, and its advantages were discussed. Our technical strategy may be helpful in the production of other chemicals from hemicellulosic hydrolysates.

\section{Results and discussion}

\section{Screening and characterization of target yeast strains}

WXML contains approximately $800 \mathrm{~g} / \mathrm{L}$ of total sugars and $5-10 \mathrm{~g} / \mathrm{L}$ of furan compounds (mainly furfural and HMF), with a density of $1.25 \mathrm{~g} / \mathrm{L}$ and a low $\mathrm{pH}$ at 3.54.5 , thus presenting a harsh environment for microbial survival. In general, longer storage time would lead to more yeast strains enriched in the WXML samples. In the case of yeast strain screening, we used samples from WXML stored for several years in factories rather than fresh WXML. This may help to collect the yeast strains that can survive in WXML containing high concentrations of inhibitors. Only the strains that grew well on both WXML plates and xylose plates were collected and further cultivated for at least 20 rounds on WXML plates for adaption (Fig. 2a). Following the above procedure, we chose one from several candidates and designated it as $C$. tropicalis X828 based on the sequences of its 18S rDNA (99\% in homology test) and internal transcribed spacer (ITS) region (100\% in homology test).

The detoxification of WXML was performed in a complex YCN medium (complex medium in which nitrogen sources included yeast extract, corn syrup powder and $\left.\left(\mathrm{NH}_{4}\right)_{2} \mathrm{HPO}_{4}\right)$ containing $400 \mathrm{~g} / \mathrm{L} \mathrm{WXML}$ and the concentration of furfural and HMF was estimated at 2.1 and
$1.5 \mathrm{~g} / \mathrm{L}$. Analysis by high-performance liquid chromatography (HPLC) and measurement of biotransformation aliquots at their peak absorbance at $280 \mathrm{~nm}\left(\mathrm{~A}_{280}\right)$ demonstrated that furfural and HMF could be depleted in about $40 \mathrm{~h}$ (Fig. 2b, c). The results show that the detoxification capacity of $C$. tropicalis X828 met the requirements for further experiments; the initial cell density we used was only 0.6 at $\mathrm{OD}_{600}$. Additionally, our HPLC results also showed the presence and disappearance of two unidentified peaks (I, II) when yeast cells entered the exponential growth phase in about $24 \mathrm{~h}$ (Fig. 2b). Recently, it has been highlighted that $S$. cerevisiae strains have the ability to reduce furfural and HMF to their alcohols 2-furanmethanol (FM) and furan-2,5-dimethanol (FDM) [24-27]; two enzymes, alcohol dehydrogenase 6 (ADH6) and alcohol dehydrogenase 1 mutant (mut$\mathrm{ADH} 1$ ), have been identified as the enzymes responsible for the reduction of furfural and HMF in S. cerevisiae [28, 29]. Almeida et al. [30] found that xylose reductase from Pichia stipitis (Ps-XR) is able to reduce HMF to its alcohol both in vitro and in vivo and suggested that Ps-XR also has furaldehyde reduction abilities. It has been suggested that the accumulation of these metabolites may be less toxic to yeast cells than their aldehyde forms [29, 31]. Based on the above reports, the unidentified peaks were speculated to be their alcohol compounds, and this needs further investigation.

The strain C. tropicalis X828 grew very well and formed large colonies $(2-3 \mathrm{~mm}$ in diameter) within approximately $60 \mathrm{~h}$ on solid plates containing $500 \mathrm{~g} / \mathrm{L}$ WXML; however, in the liquid YCN medium containing WXML at the same concentration, the cell growth almost stopped and the cell concentration reached only 1-2 at $\mathrm{OD}_{600}$ in $48 \mathrm{~h}$ (Fig. 2d). In contrast, the initial concentrations of WXML ranging from 100 to $400 \mathrm{~g} / \mathrm{L}$ supported its growth well and biomass of more than 23 at $\mathrm{OD}_{600}$ could be achieved at the end of cultivation (Fig. 2d). Correspondingly, the conversion rate of xylose was also decreased in the presence of $500 \mathrm{~g} / \mathrm{L}$ WXML due to poor biomass formation (Fig. 2e). Additionally, fewer sugars in the medium, i.e. a content of $100 \mathrm{~g} / \mathrm{L} \mathrm{WXML,}$ also decreased the xylose conversion rate (Fig. 2e). In fact, under the conditions of $100 \mathrm{~g} / \mathrm{L}$ WXML, other sugars such as glucose, galactose but L-arabinose were also exhausted at the end of cultivation due to the metabolic demands of cellular growth (data now shown). The maximum yield of xylitol, approximately $46 \%$, was observed only when using $400 \mathrm{~g} / \mathrm{L}$ WXML (Fig. 2e). Through the biodetoxification by yeast cells, the $127 \mathrm{~g} / \mathrm{L}$ of xylose from $400 \mathrm{~g} / \mathrm{L}$ WXML was converted into $59 \mathrm{~g} / \mathrm{L}$ of xylitol, the glucose $(13.5 \mathrm{~g} / \mathrm{L})$ was exhausted, and the two by-product sugars $\mathrm{L}$-arabinose $(45.2 \mathrm{~g} / \mathrm{L})$ and galactose $(11 \mathrm{~g} / \mathrm{L})$, remained. 


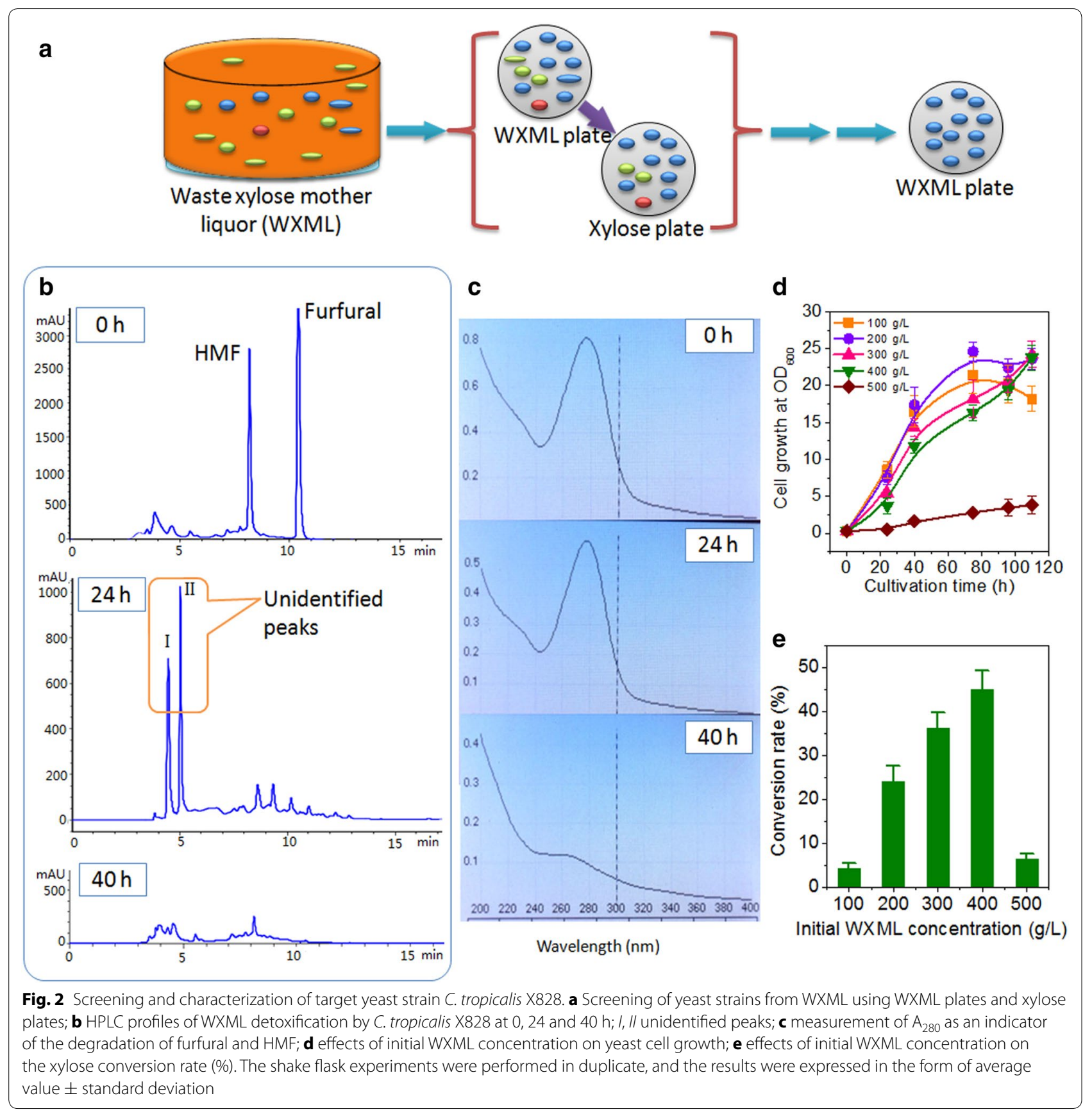

\section{Screening of $B$. subtilis strains and sugar metabolism by complementary strain Bs 12}

Results from plates showed that C. tropicalis X828 was poor in its capacity to deplete L-arabinose, which is the most prevalent by-product sugar in WXML. Thus, to complete the one-pot biotransformation complementary strains were necessary. $B$. subtilis, well known as an aerobe commonly found in soil, can metabolize a variety of sugars. The complementary strain should consume
L-arabinose and galactose but not the final product xylitol (Fig. 3a). In our previous study, we have shown that the $x y l$ A gene-disrupted $B$. subtilis 168 lose its ability to metabolize xylitol [5]. Thus, we decided to use the $x y l$ A gene-disrupted $B$. subtilis 168 as a starter strain to further improve its adaptability on the detoxified WXML plates (Fig. 3a). Only the top five colonies that grew well on the plates were chosen and applied to the next round of adaption. Following the above procedure, 

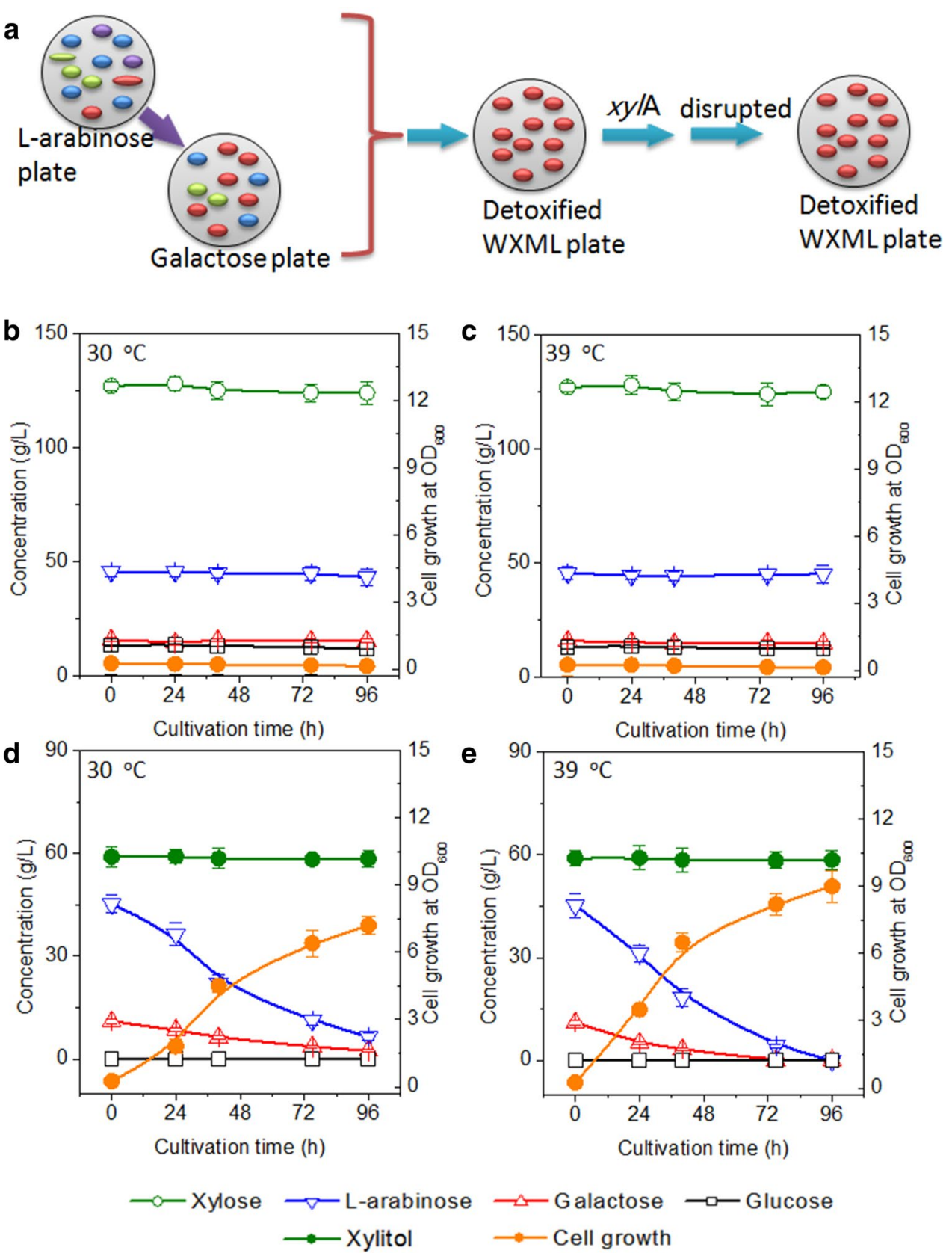

Fig. 3 Screening and characterization of complementary strain B. subtilis Bs12. a Screening of complementary strains for the target yeast strain using L-arabinose or galactose containing NSM plates. The complementary strain was then cultivated for 20-30 rounds on detoxified WXML plates. $x y / A$, xylose isomerase gene $x y / A$; Sugar metabolism of the complementary strain B. subtilis Bs 12 is shown in medium containing undetoxified WXML at $30^{\circ} \mathrm{C}(\mathbf{b})$ and $39^{\circ} \mathrm{C}(\mathbf{c})$ and in detoxified WXML medium at $30^{\circ} \mathrm{C}(\mathbf{d})$ and $39^{\circ} \mathrm{C}(\mathbf{e})$. The shake flask experiments were performed in duplicate, and the results were expressed in the form of average value \pm standard deviation

we obtained a well-adapted strain and designated it as $B$. subtilis Bs12.

However, when cultivated in YCN medium containing $400 \mathrm{~g} / \mathrm{L}$ of undetoxified WXML, strain Bs12 showed no signs of cell growth or sugar metabolism at 30 or $39^{\circ} \mathrm{C}$ (Fig. 3b, c), but in YCN medium containing detoxified
WXML, it grew to approximately 7.2 at $\mathrm{OD}_{600}$ within $96 \mathrm{~h}$ from an initial cell concentration of 0.25 at $\mathrm{OD}_{600}$ (Fig. 3d). At $30{ }^{\circ} \mathrm{C}$, this strain degraded $\mathrm{L}$-arabinose $(45.2 \mathrm{~g} / \mathrm{L})$ and galactose $(11 \mathrm{~g} / \mathrm{L})$ to approximately 6.5 and $2.4 \mathrm{~g} / \mathrm{L}$ within $96 \mathrm{~h}$ (Fig. $3 \mathrm{~d}$ ). When the cultivation temperature was increased to $39^{\circ} \mathrm{C}$, its cell growth was 
improved and L-arabinose and galactose were completely depleted within $96 \mathrm{~h}$ (Fig. 3e). The concentration of xylitol remained constant throughout the cultivation, suggesting that $B$. subtilis Bs 12 could not metabolize xylitol and thus it was suitable for subsequent purification experiments (Fig. 3e). These results suggest a promising scheme for the biotransformation of xylose from WXML and purification by the consumption of by-product sugars using two complementary strains.

\section{Complementary biotransformation of xylose from WXML by $C$. tropicalis X828 and B. subtilis Bs 12 in shake flasks}

In the above experiments, we tested the existence of complementary metabolic pathways in the two strains on plates. To run a successful complementary transformation, we also needed to test their integration efficiency to make both match for each other in one bioreactor. In the experiments of complementary biotransformation, precultures of yeast strain X828 and B. subtilis Bs12 were inoculated at the same time into YCN medium containing $400 \mathrm{~g} / \mathrm{L}$ of WXML. The $13.5 \mathrm{~g} / \mathrm{L}$ of glucose in WXML was depleted first within about $24 \mathrm{~h}$ and the by-product sugars, $15.5 \mathrm{~g} / \mathrm{L}$ of galactose and $45.2 \mathrm{~g} / \mathrm{L}$ of L-arabinose, were exhausted at $96 \mathrm{~h}$ and $110 \mathrm{~h}$, respectively (Fig. 4a). Additionally, a maximum concentration of $2.2 \mathrm{~g} / \mathrm{L}$ of ethanol at $75 \mathrm{~h}$ and less than $1 \mathrm{~g} / \mathrm{L}$ of arabitol at $110 \mathrm{~h}$ were also observed. At the end of biotransformation, only $59 \mathrm{~g} / \mathrm{L}$ of xylitol was obtained from $127 \mathrm{~g} / \mathrm{L}$ of xylose, and the conversion rate was estimated at approximately $46 \%$ (Fig. 4a). In fact, the maximum yield of xylitol was observed at approximately $80-96 \mathrm{~h}$, but at that moment, a total of $15 \mathrm{~g} / \mathrm{L}$ of by-product sugars was still left in the medium.

The addition of $15 \mathrm{~g} / \mathrm{L}$ glucose at $40 \mathrm{~h}$, following the depletion of the initial glucose from WXML, increased the final production of xylitol to $94.5 \mathrm{~g} / \mathrm{L}$ and the final conversion rate reached $73 \%$ (Fig. $4 \mathrm{~b}$ ). When there was low content of sugars from WXML, for example, $100 \mathrm{~g} / \mathrm{L}$ of WXML (Fig. 2e), most of the sugars including xylose would be depleted at the end of cultivation, suggesting that a sufficient amount of glucose was indeed required to avoid xylose consumption for cellular growth. Similar results from Yahashi et al. [32] also suggested that yeast cells consume xylose for the production of xylitol
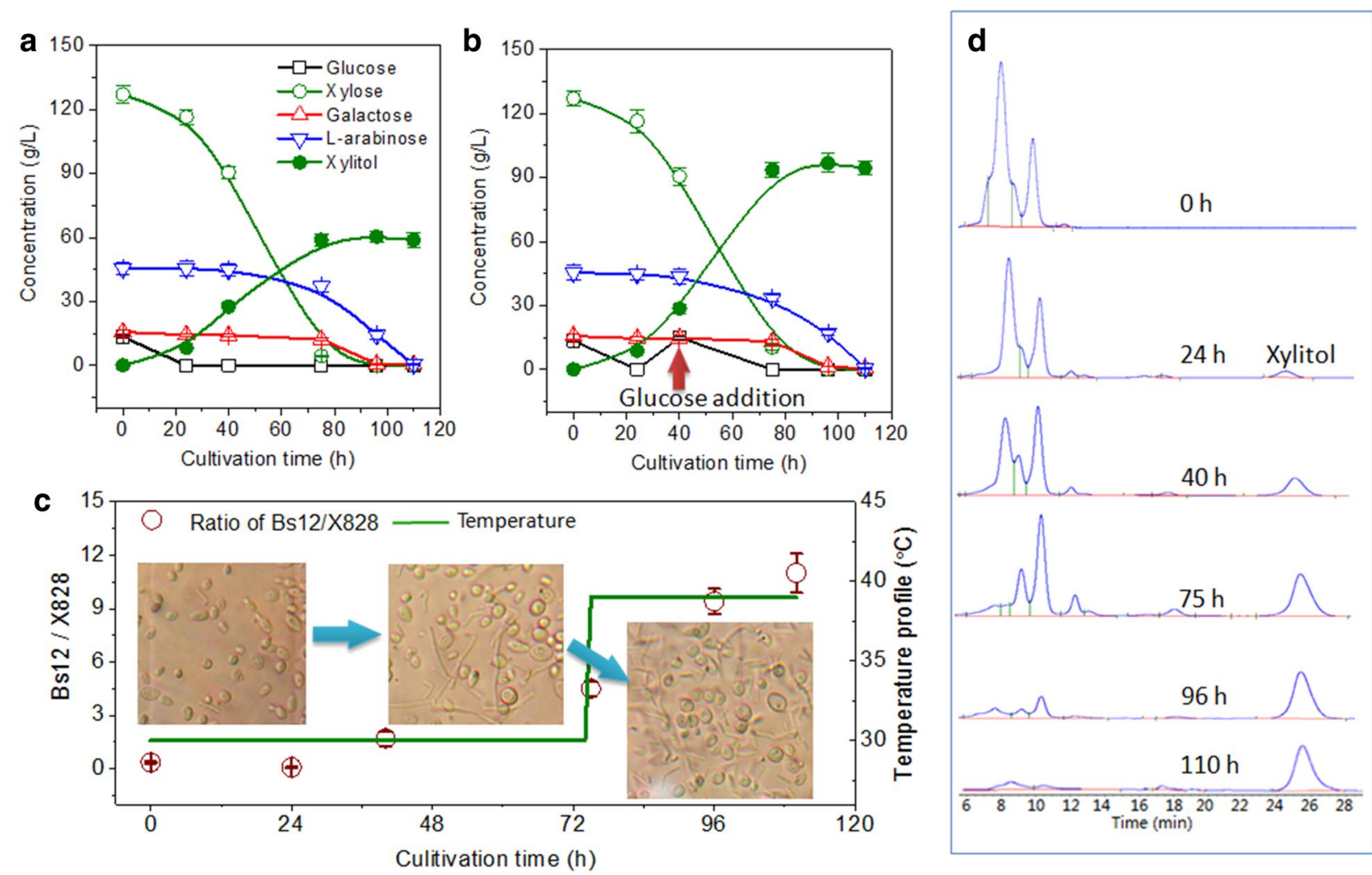

Fig. 4 Complementary biotransformation of WXML by C. tropicalis X828 and B. subtilis Bs 12 in shake flasks. $\mathbf{a}$, b Batch biotransformation and glucose fed-batch biotransformation; the arrow represents the addition of $15 \mathrm{~g} / \mathrm{L}$ glucose at $40 \mathrm{~h}$; c ratio of strain Bs 12 and X828 cells in glucose fed-batch biotransformation; $\mathbf{d ~ H P L C}$ profiles of xylitol production. The shake flask experiments were performed in duplicate, and the results were expressed in the form of average value \pm standard deviation 
as well as for cell growth and maintenance, thus resulting in decreased xylitol yield. However, in the case of xylitol production by a recombinant $S$. cerevisiae strain containing a xylose reductase gene from Pichia stipitis, supplemented glucose above $0.35 \mathrm{~g} / \mathrm{L}$ inhibited xylose uptake and caused ethanol accumulation up to $48 \mathrm{~g} / \mathrm{L}$ [33]. This suggests that the choice of yeast strain, xylose content as well as glucose supplementation are crucial to obtain a high yield of xylitol.

Figure 4c shows that the initial ratio of Bs12/X828 cell concentrations was approximately 0.36 at $0 \mathrm{~h}$ and decreased to 0.08 at $24 \mathrm{~h}$ due to the cell growth of yeast strain X828 under the stress of the inhibitors furfural and HMF. After 48 h, B. subtilis strain Bs12 outgrew yeast cells and continued to grow to a final ratio of 11 . The growth improvement of strain Bs 12 was mainly due to the depletion of furaldehyde inhibitors by yeast strain X828 and an increase in temperature to $39{ }^{\circ} \mathrm{C}$ at $72 \mathrm{~h}$. From 75 to $110 \mathrm{~h}$, the maximum consumption rates of galactose and L-arabinose reached 0.5 and $1.0 \mathrm{~g} /(\mathrm{L} \cdot \mathrm{h})$ with the fast growth of strain Bs12 (Fig. 4b, c). Figure 4d demonstrates the HPLC profiles of xylitol production and the consumption of by-product sugars. Especially during the aerobic period $(75-110 \mathrm{~h}$ ), approximately $80 \%$ of all the by-product sugars were consumed (Fig. 4b, d). At the end of biotransformation, the by-product sugars were depleted to less than $4 \mathrm{~g} / \mathrm{L}$ in total concentration, and the purity of xylitol produced was estimated at $95 \%$. The biomass produced was approximately $3.2 \mathrm{~g} / \mathrm{L}$ dry cell weight (DCW) thus facilitating the subsequent xylitol extraction procedure by simply removing the cells.

\section{Complementary biotransformation of xylose from WXML in bioreactors}

Based on the above results from shake flasks, we summed up the operating points: one-off inoculation, two-stage biotransformation and glucose supplementation. The batch biotransformation experiment in bioreactors was first performed on the scale of $5 \mathrm{~L}$ (Fig. 5a). At the first stage of micro-aerobic biotransformation $(0-72 \mathrm{~h})$, the yeast cells were allowed to grow and metabolized the inhibitors furfural and HMF, and approximately $82 \%$ of the initial xylose (initial concentration $=127 \mathrm{~g} / \mathrm{L}$ ) was consumed/transformed and $82 \mathrm{~g} / \mathrm{L}$ of xylitol was produced, while only $25 \%$ of L-arabinose (initial concentration $=45.4 \mathrm{~g} / \mathrm{L}$ ) and $22 \%$ of galactose (initial concentration $=15.3 \mathrm{~g} / \mathrm{L}$ ) was depleted. In contrast, the $13.5 \mathrm{~g} / \mathrm{L}$ of initial glucose from WXML was exhausted as early as $24 \mathrm{~h}$ (data not shown), and more glucose ( $15 \mathrm{~g} / \mathrm{L})$ was then supplemented at $40 \mathrm{~h}$ to allow the transformation to continue into the second stage. At the second stage of aerobic biotransformation (72-110 h), with the fast cell growth of strain Bs12 the consumption rates of L-arabinose and galactose increased, and the rest of $\mathrm{L}$-arabinose $(34 \mathrm{~g} / \mathrm{L})$ and galactose $(12 \mathrm{~g} / \mathrm{L})$ were depleted at approximately $96-110 \mathrm{~h}$ (Fig. 5a). At the end of biotransformation, $95 \mathrm{~g} / \mathrm{L}$ of xylitol was produced and the overall conversion rate was estimated to be approximately $74 \%$ (Fig. 5a). This represented a yield of $82 \%$ of the theoretical value, which was computed to be $0.74 \mathrm{~mol}$ xylitol per mol xylose. The profiles of xylose biotransformation preformed in the $150 \mathrm{~L}$ and $30 \mathrm{~m}^{3}$ bioreactors were similar to the results from the $5 \mathrm{~L}$ bioreactor (Fig. 5b, c).

The detailed conversion rates of xylose at different stages were from three batches of biotransformation conducted in a $5 \mathrm{~L}$ bioreactor (Fig. $5 \mathrm{~d}$ ). Figure $5 \mathrm{~d}$ demonstrates that the maximum conversion rate (approximately $77 \%$ ) was from the period of $40-75 \mathrm{~h}$ when there was a large amount of xylose and sufficient glucose for cell metabolism (Fig. 5a). The conversion rate at 75-96 h dropped to $55 \%$, suggesting that further optimization might be helpful. The oxidation-reduction balance of pyridine nucleotide cofactor $\left(\mathrm{NADP}^{+}\right)$is of great concern in xylitol biotransformation. Barbosa et al. [34] showed that the maximum yield of xylitol was $0.905 \mathrm{~mol}$ xylitol per mol of xylose consumed if NADPH was completely regenerated via the pentose phosphate pathway. However, with cell growth, the xylitol yield should be less than the theoretical value, since some of xylose is always consumed for cellular metabolism. Yahashi et al. [32] suggested that if a fermentation process, such as the optimization of glucose feeding, is applied to prevent xylose consumption for cellular growth and NADPH regeneration, the yield should be further increased.

\section{Comparison of two processes in the biotransformation of xylose from WXML}

Our group previously reported a method for the biotransformation of xylose from WXML, in which sugars and inhibitors were a little different from the WXML used in our present study [5]. In brief, there were four steps in our previous process: (i) Detoxification; the yeast strain C. maltosa was first inoculated into the medium containing WXML to remove the inhibitors and then collected by centrifugation. (ii) Purification; the B. subtilis strain Bsxyl was inoculated into the detoxified medium to deplete the by-product sugars $\mathrm{L}$-arabinose and galactose and the cells was then removed by centrifugation. (iii) WXML concentration; the biopurified broth was condensed to obtain a higher content of xylose. (iv) Xylose biotransformation; the above collected yeast cells catalyzed xylose into xylitol in the concentrated broth (Fig. 6a). The conversion rate of xylose in step iv was estimated at $84 \%$, but the total one was only $63 \%$ considering xylose loss in the cell precipitate during multi-step 


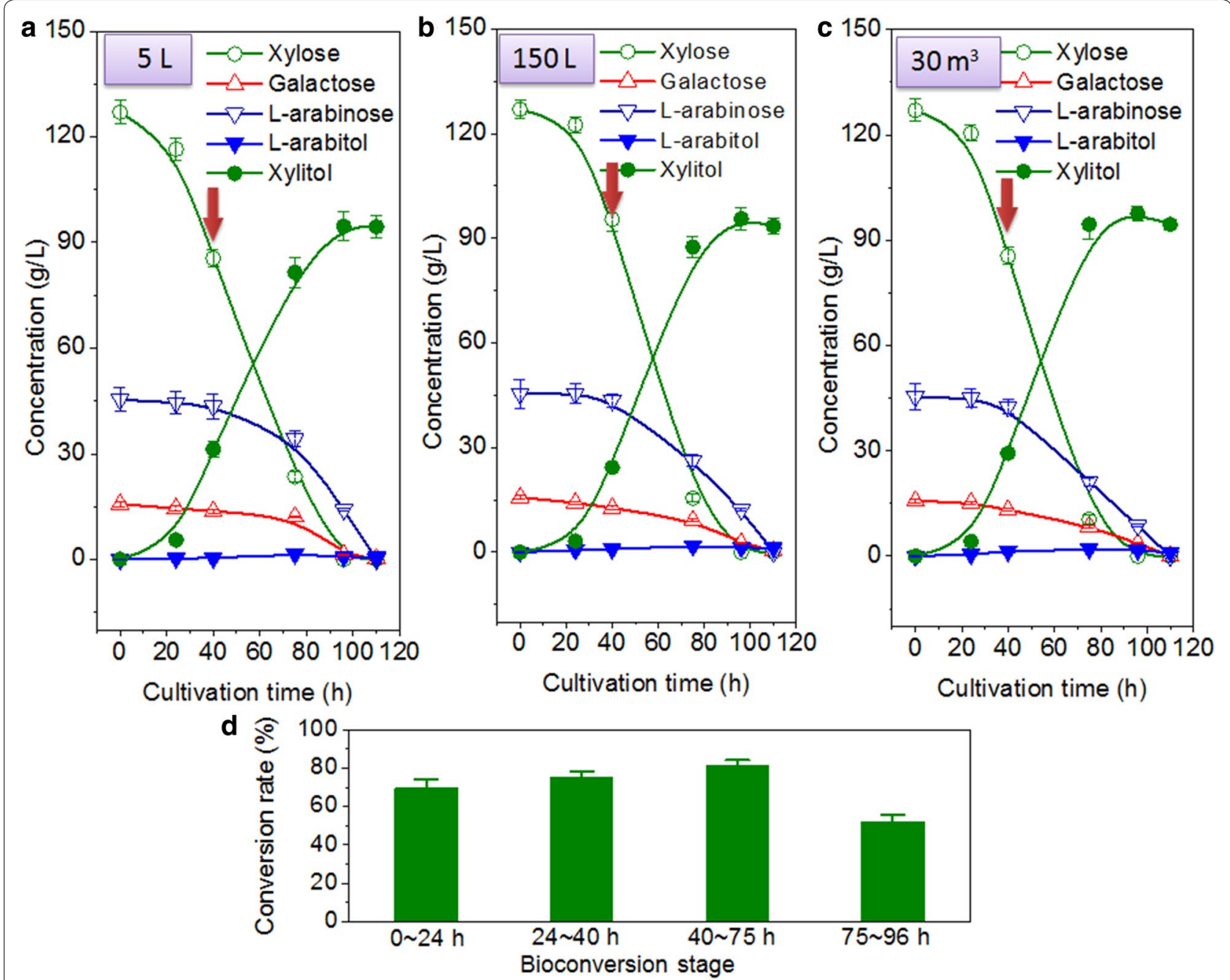

Fig. 5 Complementary biotransformation of WXML by C. tropicalis X828 and B. subtilis Bs 12 in bioreactors. Results from $5 \mathrm{~L}$ (a), $150 \mathrm{~L}$ (b), and $30 \mathrm{~m}^{3}$ (c) bioreactors are shown; the arrow represents the addition of $15 \mathrm{~g} / \mathrm{L}$ glucose at $40 \mathrm{~h}$; the profiles of biotransformation conducted in bioreactors were from one batch of cultivation and expressed in the form of average value \pm standard deviation. $\mathbf{d}$ Xylose conversion rates at different growth stages in a $5 \mathrm{~L}$ bioreactor. The results were from three batches of cultivation in a $5 \mathrm{~L}$ bioreactor

centrifugation and in the conversion into by-product $\mathrm{D}$-arabitol. In the one-pot biotransformation, the yeast strain X828 and B. subtilis strain Bs12 were inoculated at the same time into WXML, and the detoxification, removal of by-product sugars, and xylose biotransformation were conducted in one bioreactor, following a two-stage cultivation procedure (Fig. 6b). The overall conversion rate in our newly developed one-pot biotransformation reached approximately $74 \%$. Additionally, our previous four-step biotransformation of xylose took about 10 days while the newly developed one-pot biotransformation took $110 \mathrm{~h}$ (Fig. 6).

Recently, there have been many papers published on xylitol production by the biotransformation of purified xylose and hemicellulosic hydrolysates, using one yeast strain obtained from screening or genetic modification. Kwon et al. [35] reported that they obtained $234 \mathrm{~g} / \mathrm{L}$ xylitol form $260 \mathrm{~g} / \mathrm{L}$ of pure xylose using C. tropicalis by fed-batch fermentation. Walther et al. studied the influence of hemicellulosic sugars on xylitol production by $C$. tropicalis, and demonstrated that the maximum xylitol yield $(0.84 \mathrm{~g} / \mathrm{g}$ xylose) was obtained using a synthetic medium containing high arabinose and low glucose and mannose contents [36]. However, the industrial production of xylitol is still carried out by chemical hydrogenation of pure xylose due to the cost of biotransformation in terms of industrial investment and processing time [1-3]. In recent years, xylitol production directly from 


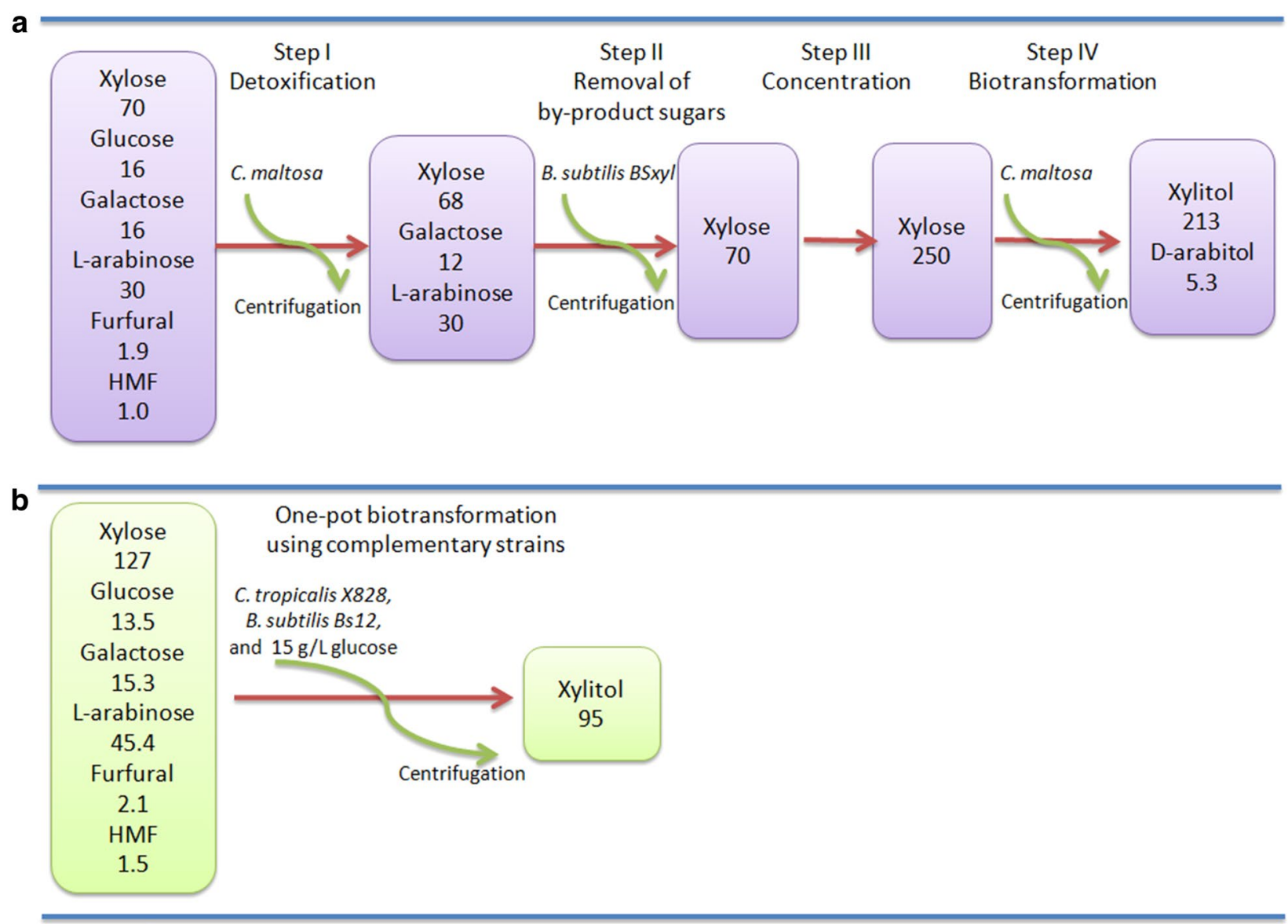

Fig. 6 Comparison of two processes in the biotransformation of xylose from WXML. a Complementary biotransformation using C. maltosa and $B$. subtilis Bsxyl in our previous study; b one-pot biotransformation using C. tropicalis X828 and B. subtilis Bs12

hemicellulosic hydrolysates has made great progress. For instance, Ling et al. [37] optimized the culture medium in xylitol production by $C$. tropicalis HDY-02 and showed that $58 \mathrm{~g} / \mathrm{L}$ of xylitol with a yield of $0.73 \mathrm{~g} / \mathrm{g}$ xylose could be produced from corncob hydrolysates by fed-batch cultivation. Zhang et al. described the production of xylitol from horticultural waste hemicellulosic hydrolysates by a new strain of Candida athensensis SB18. This strain was able to consume up to $300 \mathrm{~g} / \mathrm{L}$ of pure xylose at a yield of $0.83-0.87 \mathrm{~g} / \mathrm{g}$ xylose and produced approximately $100 \mathrm{~g} / \mathrm{L}$ of xylitol from hydrolysates that were detoxified by activated charcoal powder and concentrated using vacuum evaporation [17]. However, the above studies seldom report results from the consumption of by-product sugars, which are always produced in hemicellulosic hydrolysis. It has been reported that the crystallization of xylitol is negatively affected by the content of by-product sugars $[22,23]$. Therefore, to achieve large-scale industrial production of xylitol directly from the biomass mixtures, the removal of by-product sugars should receive more consideration in future. In our present study, to removal such miscellaneous by-product sugars we chose to make use of the existing metabolic pathways in $B$. subtilis, rather than to construct new pathways in yeast cells. Our results demonstrate that the metabolic pathways borrowed are also efficient, in particular, in the biotransformation of mixtures of various ingredients.

\section{Conclusions}

We report a one-pot strategy to make use of an organic pollutant of hemicellulosic hydrolysates WXML, which combined detoxification, biotransformation and purification in one bioreactor using two complementary strains, C. tropicalis X828 and B. subtilis Bs12. The one-pot biotransformation of WXML was successfully scaled up from shake flasks to $30 \mathrm{~m}^{3}$ bioreactors. Approximately $95 \mathrm{~g} / \mathrm{L}$ of xylitol (95\% in purity) could be obtained from $400 \mathrm{~g} / \mathrm{L}$ of WXML at a yield of $0.75 \mathrm{~g} / \mathrm{g}$ xylose consumed, and the by-product sugars glucose, L-arabinose and galactose were depleted simultaneously. Our study 
provides useful information in the combination of biotechnological processes for the biotransformation of similar compounds.

\section{Methods}

\section{Screening and identification of yeast strains}

To prepare solid medium (WXML plates) for the screening of yeast strains, $100 \mathrm{~mL}$ of WXML from different factories (stored for more than 2 years) was sterilized separately at $110{ }^{\circ} \mathrm{C}$ for $30 \mathrm{~min}$ and mixed at $50-70{ }^{\circ} \mathrm{C}$ with $100 \mathrm{~mL}$ of sterilized YP medium containing $10 \mathrm{~g} / \mathrm{L}$ yeast extract (Oxoid, UK), $5 \mathrm{~g} / \mathrm{L}$ peptone (Oxoid, UK) and $25 \mathrm{~g} / \mathrm{L}$ agar powder. Solid YP medium containing $20 \mathrm{~g} / \mathrm{L}$ xylose (YPX) was also used for screening. Solid YP medium containing $20 \mathrm{~g} / \mathrm{L}$ glucose (YPD) was used for the estimation of colony forming units (CFU) of yeast and B. subtilis cells.

To screen yeast strains that would grow well on WXML plates, the microbial cells were collected by centrifugation of $50 \mathrm{~mL}$ WXML at 10,000 $g$ for $20 \mathrm{~min}$, re-suspended in sterile water, spread on WXML plates and cultivated at $30^{\circ} \mathrm{C}$ for several days. For each round of cultivation, the top five largest yeast colonies were selected and subjected to the next cultivation step. In our experiments, most bacteria could not grow within 5 days on the WXML plates containing $500 \mathrm{~g} / \mathrm{L}$ WXML.

Yeast strains were identified by the sequences of their $18 \mathrm{~S}$ rDNA and ITS region, and genomic DNA was extracted using the phenol lysis method [38]. The primers used for amplification of $18 \mathrm{~S}$ rDNA were $5^{\prime}$-ATC CTG CCA GTA GTC ATA TGC TTG TCT C- $3^{\prime}$ and $5^{\prime}$-GAG GCC TCA CTA AGC CAT TCA ATC GGT A- ${ }^{\prime}$ and those for ITS were $5^{\prime}$-TCC TCC GCT TAT TGA TAT GC- $3^{\prime}$ and $5^{\prime}$-TTC GTA GGT GAA CCT GCG G- $3^{\prime}$. PCR conditions were as follows: $94{ }^{\circ} \mathrm{C}$ for $5 \mathrm{~min}, 35$ cycles of denaturation at $94{ }^{\circ} \mathrm{C}$ for $30 \mathrm{~s}$, annealing at $55^{\circ} \mathrm{C}$ for $30 \mathrm{~s}$, extension at $72{ }^{\circ} \mathrm{C}$ for $90 \mathrm{~s}$, and a final extension at $72{ }^{\circ} \mathrm{C}$ for $10 \mathrm{~min}$. Purified PCR product was ligated into T-vector (pMD18, Takara, Dalian, China) and sequenced. The sequence analysis was conducted using the basic local alignment search tool (BLAST) from National Center for Biotechnology Information (NCBI).

\section{Screening and adaption of $B$. subtilis strains}

The solid nitrogen and salts medium (NSM) used to screen B. subtilis strains contained $2 \mathrm{~g} / \mathrm{L}\left(\mathrm{NH}_{4}\right)_{2} \mathrm{SO}_{4}$, $1 \mathrm{~g} / \mathrm{L}$ casamino acids (AMRESCO), $0.5 \mathrm{~g} / \mathrm{L}$ tryptophan, $5 \mathrm{~g} / \mathrm{L} \mathrm{Na}_{2} \mathrm{HPO}_{4} \cdot 12 \mathrm{H}_{2} \mathrm{O}, 0.5 \mathrm{~g} / \mathrm{L} \mathrm{KH}_{2} \mathrm{PO}_{4}, 0.2 \mathrm{~g} / \mathrm{L} \mathrm{CaCl}$, $0.5 \mathrm{~g} / \mathrm{L} \mathrm{MgSO}_{4} \cdot 7 \mathrm{H}_{2} \mathrm{O}, 0.005 \mathrm{~g} / \mathrm{L} \mathrm{MnCl}_{2}, 0.005 \mathrm{~g} / \mathrm{L} \mathrm{FeSO}_{4}$ and $15 \mathrm{~g} / \mathrm{L}$ agar powder. To obtain a $B$. subtilis strain that could utilize L-arabinose and galactose but not xylose, all the $B$. subtilis strains from our laboratory stock were first screened on solid NSM plates containing $20 \mathrm{~g} / \mathrm{L}$ L-arabinose or galactose, and then cultured at $37^{\circ} \mathrm{C}$ for $20-30$ rounds on solid NSM plates containing $200 \mathrm{~g} / \mathrm{L}$ detoxified liquid WXML to further improve its adaptability. For each round of cultivation, the top five largest colonies were selected for their fast growth. After the above screening, we found the $x y l$ A gene-disrupted $B$. subtilis 168 grew well on L-arabinose and galactose but not xylitol [5]. So we used the $x y l$ A gene-disrupted B. subtilis 168 as a starter strain in the following adaption on detoxified WXML plates.

\section{Biotransformation and detoxification of WXML by yeast cells in shake flasks}

The complex medium used for biotransformation (YCN medium) contained $5 \mathrm{~g} / \mathrm{L}$ yeast extract (AngelYeast Co. Ltd, China), $5 \mathrm{~g} / \mathrm{L}$ corn syrup powder, $2 \mathrm{~g} / \mathrm{L}\left(\mathrm{NH}_{4}\right)_{2} \mathrm{HPO}_{4}$ and $0.5 \mathrm{~g} / \mathrm{L} \mathrm{MgSO}_{4} \cdot 7 \mathrm{H}_{2} \mathrm{O}(\mathrm{pH}$ 6.0). To prepare the yeast preculture, several colonies were inoculated into $\mathrm{YCN}$ medium containing $50 \mathrm{~g} / \mathrm{L}$ glucose and cultivated at $30{ }^{\circ} \mathrm{C}$ for about $30 \mathrm{~h}$. To start the biotransformation and detoxification, $1 \mathrm{~mL}$ of yeast preculture $\left(\mathrm{OD}_{600}=30 \pm 3\right)$ was inoculated to $50 \mathrm{~mL}$ of YCN medium containing 100 , 200, 300, 400 and $500 \mathrm{~g} / \mathrm{L}$ of WXML and cultivated at $30^{\circ} \mathrm{C}$ for $110 \mathrm{~h}$. All experiments were conducted in duplicate in $250 \mathrm{~mL}$ Erlenmeyer flasks on a $30 \mathrm{~mm}$ orbital shaker at $150 \mathrm{rpm}$. Cell growth was determined by measurement of the optical density (OD) at $600 \mathrm{~nm}\left(\mathrm{OD}_{600}\right)$. Sugars and sugar alcohols were analyzed by HPLC. Furfural and HMF were analyzed using both HPLC and absorbance at $280 \mathrm{~nm}$ [5]. The conversion rate of xylose (in \%) was calculated by the formula of $98.7 \times(\mathrm{g}$ xylitol produced/g xylose consumed).

\section{Purification of WXML by B. subtilis cells in shake flasks}

The purification experiments were performed in yeasttreated WXML using untreated WXML as control. The yeast-treated WXML was prepared as described in the above biotransformation and detoxification. In brief, $1 \mathrm{~mL}$ of yeast preculture was inoculated into the $\mathrm{YCN}$ medium containing $400 \mathrm{~g} / \mathrm{L} \mathrm{WXML} \mathrm{(supplemented} \mathrm{with}$ $15 \mathrm{~g} / \mathrm{L}$ glucose at about $40 \mathrm{~h}$ ) and cultivated for about $110 \mathrm{~h}$. The medium was then centrifuged to remove yeast cells and sterilized at $110{ }^{\circ} \mathrm{C}$ for 20 min for purification experiments. The detoxified WXML medium contained approximate xylitol $(59 \mathrm{~g} / \mathrm{L}), \mathrm{L}$-arabinose $(45.2 \mathrm{~g} / \mathrm{L})$ and galactose $(11 \mathrm{~g} / \mathrm{L})$, but no glucose or inhibitors. To prepare the B. subtilis preculture, several colonies were inoculated to the YCN medium containing $20 \mathrm{~g} / \mathrm{L}$ glucose and cultivated for about $24 \mathrm{~h}$ to reach $12 \pm 2$ at $\mathrm{OD}_{600}$. At inoculation, $1 \mathrm{~mL}$ of $B$. subtilis preculture was inoculated into $50 \mathrm{~mL}$ of the yeast-treated WXML and cultivated at 
30 and $39{ }^{\circ} \mathrm{C}$. All experiments were conducted in duplicate in $250 \mathrm{~mL}$ Erlenmeyer flasks on a $30 \mathrm{~mm}$ orbital shaker at $250 \mathrm{rpm}$.

\section{Complementary biotransformation of WXML in shake flasks}

The precultures of yeast and B. subtilis were prepared as in the above biotransformation, detoxification and purification experiments. In brief, $1 \mathrm{~mL}$ of yeast precultures $\left(\mathrm{OD}_{600}=30 \pm 3\right)$ and $1 \mathrm{~mL}$ of $B$. subtilis precultures $\left(\mathrm{OD}_{600}=12 \pm 2\right)$ were inoculated at the same time into $50 \mathrm{~mL}$ of sterilized YCN medium containing $400 \mathrm{~g} / \mathrm{L}$ of WXML. If necessary, $15 \mathrm{~g} / \mathrm{L}$ of glucose was supplemented following the exhaustion of initial glucose. Fermentation conditions were set in two stages; in the first one, the temperature and shaking speed were $30{ }^{\circ} \mathrm{C}$ and $150 \mathrm{rpm}$, and in the second one, these parameters were changed to $39^{\circ} \mathrm{C}$ and $250 \mathrm{rpm}$. The ratio of B. subtilis and yeast cells was estimated from their CFU on YPD agar plates. All the shake flask experiments were performed in duplicate, and the results were expressed in the form of average value \pm standard deviation.

\section{Complementary biotransformation of WXML in bioreactors} Batch biotransformation of WXML in bioreactors was carried out in a BIOSTAT ${ }^{\circledR}$ Aplus 5 L microbial bioreactor (Sartorius) containing $3 \mathrm{~L}$ of YCN medium supplemented with $400 \mathrm{~g} / \mathrm{L}$ WXML. Seed cultures from the $30 \mathrm{~h}$ culture of yeast and the $24 \mathrm{~h}$ culture of $B$. subtilis were inoculated into the bioreactor with $5.0 \%(\mathrm{v} / \mathrm{v})$ inoculum. The medium pH was controlled at 6.0 using $25 \%$ $\mathrm{NaOH}$ solution and $15 \mathrm{~g} / \mathrm{L}$ of glucose was supplemented following the exhaustion of initial glucose from WXML. At the stage of micro-aerobic biotransformation, the conditions were set as temperature $30^{\circ} \mathrm{C}$, aeration $0.3 \mathrm{VVM}$ and agitation $200 \mathrm{rpm}$. At the completion of biotransformation, the conditions were set as temperature $39{ }^{\circ} \mathrm{C}$, aeration 1 VVM and agitation $300 \mathrm{rpm}$ to allow for aerobic biotransformation. Samples were withdrawn periodically and centrifuged at 10,000 $\mathrm{g}$ for $20 \mathrm{~min}$ for HPLC analysis. Medium glucose was also monitored offline using a GOD-POD kit (RSBIO, Shanghai, China) according to the manufacturer's instructions.

In the case of scaled up experiments, the batch biotransformation was performed in $150 \mathrm{~L}$ and $30 \mathrm{~m}^{3}$ bioreactors following the same conditions as in the $5 \mathrm{~L}$ bioreactor with some modifications: the filling volume was $100 \mathrm{~L}$ and $20 \mathrm{~m}^{3}$, respectively; at the stage of micro-aerobic biotransformation, the aeration was set at $0.2 \mathrm{VVM}$ and agitation at $60 \mathrm{rpm}$, and at the stage of aerobic transformation the parameters were $0.5 \mathrm{VVM}$ and $100 \mathrm{rpm}$.

\section{Analytical methods}

Dry cell weight (DCW) was measured using microbial cells from $50 \mathrm{~mL}$ of biotransformation solution. In brief, wet cell pellets were first washed twice using de-ionized water, centrifuged at $10,000 \mathrm{~g}$ for $5 \mathrm{~min}$ to remove water, and dried at $105{ }^{\circ} \mathrm{C}$ to a constant weight. Analysis of sugar and sugar alcohols was performed on an HPLC system equipped with a Shodex RI 101 refractive index detector (RID). Prior to analysis, samples were centrifuged at 10,000 $\mathrm{g}$ for $10 \mathrm{~min}$, filtered through $0.22 \mu \mathrm{m}$ syringe filters and diluted if necessary. Xylose, L-arabinose, glucose, galactose, xylitol and ethanol were separated on a prepacked analytical HPLC columns (Shodex SP0810, $8 \times 30 \mathrm{~mm}, \mathrm{~Pb}^{2+}$ cation-exchange column) at $70{ }^{\circ} \mathrm{C}$ using distilled water as eluent at a flow rate of $1.0 \mathrm{~mL} / \mathrm{min}$. Analysis of furfural, HMF and their alcohols were performed using both HPLC and spectrophotometric method. In brief, $2 \mathrm{~mL}$ aliquots of the broth from the biotransformation experiment were reduced to dryness by lyophilization, and then the resulting materials were re-suspended in $1 \mathrm{~mL}$ of acetonitrile and filtered through a $0.45 \mu \mathrm{m}$ nylon filter. Analysis was performed using reverse-phase HPLC equipped with an Eclipse XDB-C18 column (Bio-Rad, USA) set at $30{ }^{\circ} \mathrm{C}$ and a UV detector set at $280 \mathrm{~nm}$. The mobile phase in this case consisted of acetonitrile: water (in v/v, 10 to $100 \%$ in $15 \mathrm{~min}, 100 \%$ for $10 \mathrm{~min}, 100$ to $10 \%$ in $2 \mathrm{~min}$, and $10 \%$ for $5 \mathrm{~min}$ ) at a flow rate of $0.5 \mathrm{~mL} / \mathrm{min}[24,25,39]$. To determine the removal of furfural and HMF, measurement of absorbance at $280 \mathrm{~nm}\left(\mathrm{~A}_{280}\right)$ was also adopted due to their peak absorbance at $280 \mathrm{~nm}[5,16,25,40]$.

\section{Authors' contributions}

$\mathrm{HW}$ and $\mathrm{HC}$ designed and carried out the experiments, analyzed the data and drafted the manuscript. LL, LZ and JA performed the experiments on the strain screening and HPLC analysis. HC and ZD contributed general advice, particularly on the HPLC analysis and resource support. All authors read and approved the final manuscript.

\section{Author details \\ ${ }^{1}$ Innovation and Application Institute (IAI), Zhejiang Ocean University, Zhoushan 316022, China. ${ }^{2}$ State Key Laboratory of Microbial Metabolism, School of Life Sciences and Biotechnology, Shanghai Jiao Tong University, Shanghai 200240, China.}

\section{Acknowledgements}

This project is supported by the National Basic Research Program of China (973 Program, No. 2013CB733903), the National High-tech R\&D Program (863 Program, No. 2012AA021503) and the Scientific Research Foundation (SRF, No. 22215010114), Zhejiang Ocean University. The funders had no role in study design, data collection and analysis, decision to publish, or preparation of the manuscript.

\section{Competing interests}

The authors declare that they have no competing interests.

Received: 4 January 2016 Accepted: 3 May 2016

Published online: 16 May 2016 


\section{References}

1. Granström TB, Izumori K, Leisola M. A rare sugar xylitol. Part II: biotechnological production and future applications of xylitol. Appl Microbiol Biotechnol. 2007;74:273-6.

2. Mikkola JP, Salmi T, Sjöholm R. Modelling of kinetics and mass transfer in the hydrogenation of xylose over Raney nickel catalyst. J Chem Technol Biotechnol. 1999:74:655-62.

3. Mikkola JP, Salmi T. In-situ ultrasonic catalyst rejuvenation in three-phase hydrogenation of xylose. Chem Eng Sci. 1999;54:1583-8.

4. Wisniak J, Hershkowitz M, Leibowitz R, Stein S. Hydrogenation of xylose to xylitol. Ind Eng Chem Res. 1974;13:75-9.

5. Cheng HR, Wang B, LV JY, Jiang MG, Lin SJ, Deng ZX. Xylitol production from xylose mother liquor: a novel strategy that combines the use of recombinant Bacillus subtilis and Candida maltosa. Microb Cell Fact. 2011;10:5.

6. Lei H, Bao Z, Xing H, Yang Y, Ren Q, Zhao M, Huang H. Adsorption behavior of glucose, xylose, and arabinose on five different cation exchange resins. J Chem Eng Data. 2010;55:735-8.

7. Xie Y, Chin CY, Phelps DSC, Lee CH, Lee KB, Mun S, Wang NHL. A five-zone simulated moving bed for the isolation of six sugars from biomass hydrolyzate. Ind Eng Chem Res. 2005;44:9904-20.

8. de Albuquerque TL, da Silva IJ, de Macedo GR, Rocha MVP. Biotechnological production of xylitol from lignocellulosic wastes: a review. Process Biochem. 2014;49:1779-89.

9. Cheng KK, Zhang JA, Ling HZ, Ping WX, Huang W, Ge JP, Xu JM. Optimization of $\mathrm{pH}$ and acetic acid concentration for bioconversion of hemicellulosic from corncobs to xylitol by Candida tropicalis. Biochem Eng J. 2009:43:203-7.

10. Kim SM, Choi BY, Ryu YS, Jung SH, Park JM, Kim GH, Lee SK. Simultaneous utilization of glucose and xylose via novel mechanisms in engineered Escherichia coli. Metabol Eng. 2015;30:141-8.

11. Li Z, Guo X, Feng X, Li C. An environment friendly and efficient process for xylitol bioconversion from enzymatic corncob hydrolysate by adapted Candida tropicalis. Chem Eng J. 2015;263:249-56.

12. Misra S, Gupta P, Raghuwanshi S, Dutt K, Saxena RK. Comparative study on different strategies involved for xylitol purification from culture media fermented by Candida tropicalis. Sep PurifTechnol. 2011;78:266-73.

13. Misra S, Raghuwanshi S, Saxen RK. Evaluation of corncob hemicellulosic hydrolysate for xylitol production by adapted strain of Candida tropicalis. Carb Poly. 2013;92:1596-601.

14. Rao RS, Jyothi CP, Prakasham RS, Sarma PN, Rao LV. Xylitol production from corn fiber and sugarcane bagasse hydrolysates by Candida tropicalis. Bioresour Technol. 2006;97:1974-8.

15. Sirisansaneeyakul S, Staniszewski M, Rizzi M. Screening of yeasts for production of xylitol from D-xylose. J Fermen Bioeng. 1995;80:565-70.

16. Tada K, Horiuchi Jl, Kanno T, Kobayashi M. Microbial xylitol production from corn cobs using Candida magnoliae. J Biosci Bioeng. 2004;98:228-30.

17. Zhang JM, Geng AL, Yao CY, Lu YH, Li QB. Xylitol production from D-xylose and horticultural waste hemicellulosic hydrolysate by a new isolate of Candida athensensis SB18. Bioresour Technol. 2012;105:134-41.

18. Fonseca BG, de Oliveira Moutta R, de Oliveira Ferraz F, Vieira ER, Nogueira AS, Baratella BF, Rodrigues LC, Zhang HR, da Silva SS. Biological detoxification of different hemicellulosic hydrolysates using Issatchenkia occidentalis CCTCC M 206097 yeast. J Ind Microbial Biotechnol. 2011:38:199-207.

19. Huang CF, Jiang YF, Guo GL, Hwang WS. Development of a yeast strain for xylitol production without hydrolysate detoxification as part of the integration of co-product generation within the lignocellulosic ethanol process. Bioresour Technol. 2011;102:3322-9.

20. Zhang D, Ong YL, Li Z, Wu JC. Biological detoxification of furfural and 5-hydroxyl methyl furfural in hydrolysate of oil palm empty fruit bunch by Enterobacter sp. FDS8. Biochem Eng J. 2013;72:77-82.

21. Mussatto SI, Santos JC, Ricardo Filho WC, Silva SS. A study on the recovery of xylitol by batch adsorption and crystallization from fermented sugarcane bagasse hydrolysate. J Chem Technol Biotechnol. 2006;81:1840-5.
22. Rivas B, Torre P, Domínguez JM, Converti A, Parajó JC. Purification of xylitol obtained by fermentation of corncob hydrolysates. J Agric Food Chem. 2006:54:4430-5.

23. Wei J, Yuan Q, Wang T, Wang L. Purification and crystallization of xylitol from fermentation broth of corncob hydrolysates. Front Chem Eng China. 2010;4:57-64.

24. Almeida JR, Röder A, Modig T, Laadan B, Lidén G, Gorwa-Grauslund MF. $\mathrm{NADH}$-vs NADPH-coupled reduction of 5-hydroxymethyl furfural (HMF) and its implications on product distribution in Saccharomyces cerevisiae. Appl Microbial Biotechnol. 2008;78:939-45.

25. Liu ZL, Slininger PJ, Dien BS, Berhow MA, Kurtzman CP, Gorsich SW. Adaptive response of yeasts to furfural and 5-hydroxymethylfurfural and new chemical evidence for HMF conversion to 2,5-bis-hydroxymethylfuran. J Ind Microbiol Biotechnol. 2004;31:345-52.

26. Modig T, Almeida JR, Gorwa-Grauslund MF, Lidén G. Variability of the response of Saccharomyces cerevisiae strains to lignocellulose hydrolysate. Biotechnol Bioeng. 2008;100:423-9.

27. Nilsson A, Gorwa-Grauslund MF, Hahn-Hägerdal B, Lidén G. Cofactor dependence in furan reduction by Saccharomyces cerevisiae in fermentation of acid-hydrolyzed lignocellulose. Appl Environ Microbiol. 2005;71:7866-71

28. Laadan B, Almeida JR, Rådström P, Hahn-Hägerdal B, Gorwa-Grauslund M. Identification of an NADH-dependent 5-hydroxymethylfurfural-reducing alcohol dehydrogenase in Saccharomyces cerevisiae. Yeast. 2008;25:191-8.

29. Petersson A, Almeida JR, Modig T, Karhumaa K, Hahn-Hägerdal B, GorwaGrauslund MF, Lidén G. A 5-hydroxymethyl furfural reducing enzyme encoded by the Saccharomyces cerevisiae ADH6 gene conveys HMF tolerance. Yeast. 2006;23:455-64.

30. Almeida JR, Modig T, Röder A, Lidén G, Gorwa-Grauslund MF. Pichia stipitis xylose reductase helps detoxifying lignocellulosic hydrolysate by reducing 5-hydroxymethyl-furfural (HMF). Biotechnol Biofuels. 2008;1:12.

31. Larsson $S$, Cassland $P$, Jönsson LJ. Development of a Saccharomyces cerevisiae strain with enhanced resistance to phenolic fermentation inhibitors in lignocellulose hydrolysates by heterologous expression of laccase. Appl Environ Microbiol. 2001;67:1163-70.

32. Yahashi Y, Horitsu H, Kawai K, Suzuki T, Takamizawa K. Production of xylitol from D-xylose by Candida tropicalis: the effect of D-glucose feeding. J Ferment Bioeng. 1996:81:148-52.

33. Lee WJ, Ryu YW, Seo JH. Characterization of two-substrate fermentation processes for xylitol production using recombinant Saccharomyces cerevisiae containing xylose reductase gene. Process Biochem. 2000:35:1199-203.

34. Barbosa MF, de Medeiros MB, de Mancilha IM, Schneider $H$, Lee H. Screening of yeasts for production of xylitol from D-xylose and some factors which affect xylitol yield in Candida guilliermondii. J Ind Microbiol. 1988;3:241-51.

35. Kwon SG, Park SW, Oh DK. Increase of xylitol productivity by cell-recycle fermentation of Candida tropicalis using submerged membrane bioreactor. J Biosci Bioeng. 2006;101:13-8.

36. Walther T, Hensirisak P, Agblevor FA. The influence of aeration and hemicellulosic sugars on xylitol production by Candida tropicalis. Bioresour Technol. 2001;76:213-20.

37. Ling $\mathrm{H}$, Cheng $\mathrm{K}$, Ge J, Ping W. Statistical optimization of xylitol production from corncob hemicellulosic hydrolysate by Candida tropicalis HDY02. New Biotechnol. 2011:28:673-8.

38. Cheng HR, Jiang N. Extremely rapid extraction of DNA from bacteria and yeasts. Biotechnol Lett. 2006:28:55-9.

39. Koopman F, Wierckx N, de Winde JH, Ruijssenaars HJ. Identification and characterization of the furfural and 5-(hydroxymethyl) furfural degradation pathways of Cupriavidus basilensis HMF14. Proc Nat Acad Sci. 2010;107:4919-24.

40. Wahlbom CF, Hahn-Hägerdal B. Furfural, 5-hydroxymethyl furfural, and acetoin act as external electron acceptors during anaerobic fermentation of xylose in recombinant Saccharomyces cerevisiae. Biotechnol Bioeng. 2002;78:172-8. 